\title{
Comprehensive Evaluation and Influence Factors of Environmental Pollution in Manufacturing Industry of China
}

\author{
Xiao'e $\mathrm{Qu}^{*}$ \\ School of Economy and Financial Institute, Xi'an Jiaotong University, Xi'an, 710061, China \\ *Corresponding author
}

\begin{abstract}
This paper constructs a comprehensive evaluation model of environmental pollution with the characteristics of "three dimensions", then calculates the environmental pollution comprehensive index of 28 industries of China manufacturing industry from 2001 to 2013, and analyzes the influencing factors of environmental pollution. It is concluded that the industries classified as light pollution are mainly high-tech industries and clean industries, the industries classified as moderate pollution are mainly heavy and chemical industries, and the industries classified as heavy pollution mainly consisted of pollution-intensive industries and some traditional means of subsistence manufacturing; there is a trend towards a further widening of the pollution discharge gap, both within the manufacturing industry and between different industries. Increasing the R\&D investment, the proportion of clean energy and intensifying environmental regulation will help to reduce pollution emissions, while the capital to labor ratio, foreign investment, enterprise investment scale, will have negative impact on reducing pollution emissions.
\end{abstract}

Keywords-manufacturing; environmental pollution; comprehensive evaluation; influencing factors

\section{INTRODUCTION}

Since the reform and opening up, with the wave of global industrial transfer, China's manufacturing industry has gradually integrated into the international industrial specialization system and become the world's largest manufacturing country, and made an important contribution to China's economic take-off, but also paid a heavy price for the resources and environment. In order to reduce the pollution discharge per unit of output, the 16th National Congress of the CPC puts forward the new industrialization path of "low resource consumption and little environmental pollution". The outline of the "12th Five-Year" Plan clearly proposes to build a "resource-saving and environment-friendly" society. "13th Five-Year" plan further strengthens the energy-saving emission reduction constraints, China manufacturing is facing a hitherto unknown resource environment carrying capacity constraints.

In this paper, use 28 manufacturing industries in China as the research object, and make comprehensive assessment of pollutant emissions as the center to start research. Firstly, based on the advantages and evaluation principles of "vertical and horizontal", the paper constructs a comprehensive evaluation model of environmental pollution with "three-dimensional" stereoscopic characteristics, which can be compared vertically and horizontally. The model with a large promotional value has been widely applied to various comprehensive evaluation problems. The second is to select the indicators that can represent the overall pollution level of the industry, that is, $\mathrm{SO}_{2}$ emissions, soot emissions, dust emissions, waste water discharge and solid waste generation, integrating into an integrated environmental pollution index to evaluate the level of pollution emission of the manufacturing industry. Because these five indicators are highly representative and comprehensive, they are able to fully characterize the status of China's manufacturing industry pollution emissions. The third is to study the influencing factors of the change (rise or fall) of pollution emissions in the manufacturing industry, and hope to provide support for the development of targeted policy measures to reduce pollutant emissions.

\section{Evaluation Method}

At present, there are many literature on the comprehensive evaluation problems at home and abroad, however, most of them are still in the stage of theoretical research and are not mature enough [1]. Recently, a dynamic comprehensive evaluation method with "three-dimensional" characteristics has attracted wide attention from scholars. Yajun Guo [2] discussed the evaluation principle and method of vertical and horizontal pull grade method with "three dimensional" characteristics, and proved the method has objective weight, Which can meet the requirements of complexity, objectivity and dynamic comparability of environmental pollution assessment. It is especially suitable for the study of panel data evaluation.

In the comprehensive evaluation of environmental pollution in manufacturing industry of China, we should not only compare pollution situation of $m$ industries $k i$ ( $i=$ $1,2, \ldots, m)$ in a given year $t_{s}(s=1,2, \ldots, N)$, but also compare the pollution status of a certain industry in different years $t_{s}(s=1,2, \ldots, N)$. Such a set of chronological sequence of planar data tables is referred to as a temporal stereo data table, denoted by $\left\{a_{i j}\left(t_{s}\right)\right\}$, and the multi-index comprehensive evaluation with the time-series data is called dynamic comprehensive evaluation.

There are $m$ objects to be evaluated (refer to 28 manufacturing industries in this paper), taking $n$ evaluation indicators (five kinds of pollutant emission in this paper), 
and obtaining the original data in chronological order to form a three-dimensional time-series data table. See Table I .

TABLE I. TEMPORAL STEREO DATA STRUCTURES

\begin{tabular}{|c|c|c|c|c|}
\hline & $t_{1}$ & $t_{2}$ & . & $t_{N}$ \\
\hline & $a_{1}, a_{2}, \ldots, a_{n}$ & $a_{1}, a_{2}, \ldots, a_{n}$ & $\ldots$ & $a_{1}, a_{2}, \ldots, a_{n}$ \\
\hline$k_{1}$ & $a_{11}\left(t_{1}\right) \quad a_{12}\left(t_{1}\right) \quad \ldots \quad a_{1 n}\left(t_{1}\right)$ & $a_{11}\left(t_{2}\right) \quad a_{12}\left(t_{2}\right) \quad \ldots \quad a_{1 n}\left(t_{2}\right)$ & , & $a_{11}\left(t_{N}\right) \quad a_{12}\left(t_{N}\right) \quad \ldots \quad a_{1 n}\left(t_{N}\right)$ \\
\hline$k_{2}$ & $a_{21}\left(t_{1}\right) \quad a_{22}\left(t_{1}\right) \quad \ldots \quad a_{2 n}\left(t_{1}\right)$ & $a_{21}\left(t_{2}\right) \quad a_{22}\left(t_{2}\right) \quad \ldots \quad a_{2 n}\left(t_{2}\right)$ & & $a_{21}\left(t_{N}\right) \quad a_{22}\left(t_{N}\right) \ldots a_{2 n}\left(t_{N}\right)$ \\
\hline $\begin{array}{l}\cdots \\
k_{m}\end{array}$ & $\begin{array}{cccc} & \cdots \\
a_{m 1}\left(t_{1}\right) & a_{m 2}\left(t_{1}\right) & \ldots & a_{m n}\left(t_{1}\right)\end{array}$ & $\begin{array}{lllll} & \cdots \\
a_{m 1}\left(t_{2}\right) & a_{m 2}\left(t_{2}\right) & \ldots & a_{m n}\left(t_{2}\right)\end{array}$ & & $\begin{array}{llll} & \cdots & & \\
a_{m 1}\left(t_{N}\right) & a_{m 2}\left(t_{N}\right) & \ldots & a_{m n}\left(t_{N}\right)\end{array}$ \\
\hline
\end{tabular}

This kind of comprehensive evaluation problem supported by time-based three-dimensional table is called dynamic comprehensive evaluation. It can be expressed as:

$$
\begin{gathered}
y_{i}\left(t_{s}\right)=f\left(\omega_{1}\left(t_{s}\right), \omega_{2}\left(t_{s}\right), \ldots, \omega_{n}\left(t_{s}\right) ; a_{i 1}\left(t_{s}\right), a_{i 2}\left(t_{s}\right), \ldots, a_{i n}\left(t_{s}\right)\right) \\
s=1,2, \ldots, N, i=1,2, \ldots, N
\end{gathered}
$$

Here, $y_{i}\left(t_{s}\right)$ is the $k_{i}$ comprehensive evaluation value at the time $t_{\mathrm{s}}$.

Firstly, the original data sequence $\left\{a_{i j}\left(t_{s}\right)\right\}$ is normalized to ensure that the data caliber consistent and comparable, namely:

$$
z=\frac{a_{i j}\left(t_{s}\right)-\overline{a_{j}\left(t_{s}\right)}}{\sigma_{j}\left(t_{s}\right)}
$$

In the formula (2), $\mathrm{z}$ is normalized data, $\left\{a_{i j}\left(t_{s}\right)\right\}$ is the $\mathrm{j}$-th pollutant index of the i-th industry at time $t_{s} ; \overline{a_{j}\left(t_{s}\right)}$ is the mean value of the $\mathrm{j}$-th pollution index at time $t_{s} ; \sigma_{j}\left(t_{s}\right)$ is the the standard deviation of pollution index at time $t_{s}$.

Secondly, for the normalized data, the comprehensive evaluation function at $t_{s}(s=1,2, \ldots, N)$ can be expressed as:

$$
y_{i}\left(t_{s}\right)=\sum_{j=1}^{n} \omega_{j} a_{i j}\left(t_{s}\right), \sigma=1,2, \ldots, \mathrm{N}, \mathrm{l}=1,2, \ldots, \mu
$$

In the formula (3), $\omega_{j}(j=1,2, \ldots, n)$ is the weight coefficient. The weight coefficient's determining process is as follows:

Let $\delta^{2}$ be the sum of squares of total deviations of $y_{i}\left(t_{s}\right)$, denoting the overall difference of $k_{1}, k_{2}, \ldots, k_{m}$ in the time-series data table $\left\{a_{i j}\left(t_{s}\right)\right\}$. For the normalized raw data, the sum of squares of the total deviation $\delta^{2}$ can be expressed as follows:

$$
\delta^{2}=\sum_{s=1}^{N}\left[\omega^{T} H_{s} \omega\right]=\omega^{T} \sum_{s=1}^{N} H_{s} \omega=\omega^{T} H_{s} \omega
$$

Among them $\omega=\left(\omega_{1}, \omega_{2}, \ldots, \omega_{n}\right) T, H=\sum_{s=1}^{N} H_{s}$ is a $n \times n$ symmetric matrix, $H_{s}=A_{s}^{T} A_{s}(s=1,2, \ldots, N)$ and $A$ can be expressed and calculated by a real symmetric matrix:

$$
A_{s}=\left[\begin{array}{ccc}
a_{11}\left(t_{s}\right) & \ldots & a_{1 n}\left(t_{s}\right) \\
\ldots & \ldots & \ldots \\
a_{m 1}\left(t_{s}\right) & \ldots & a_{m n}\left(t_{s}\right)
\end{array}\right]_{, \sigma=1,2, \ldots, \mathrm{N}}
$$

If defining $\omega^{T} \omega=1, \omega$ is the standard feature vector corresponding to the largest eigen value of the matrix $H$. Taking the maximum value of $\delta^{2}$, and there is $\max _{\|\omega=1\|} \omega^{T} H \omega=\lambda_{\max }(H)$. When $H_{s} \succ 0(s=1,2, \ldots, N)$, there must be $H \succ 0$, and there is a normalized weighted coefficient vector $\omega$. When $H \succ 0$, the dynamic comprehensive evaluation problem (1) is transformed into (3).

According to the weight coefficient $(\omega)$ to calculate the comprehensive evaluation function $y_{i}\left(t_{s}\right)$ of formula (3). According to the size of $y_{i}\left(t_{s}\right)$ to sort the evaluation results, recording $r_{i s}$ as the order of sample $k_{i}$ at time $t_{s}$, then the maximum sequence of $k_{i}$ can be expressed as: $r_{\max i}=\max _{s}\left|r_{i s}\right|-\min _{s}\left|r_{i s}\right|, s=1,2, \ldots, N$. According to 
$r_{\max i}$, the overall pollution level of each sample in each period can be comprehensively evaluated. Since the weighting coefficient $\omega$ vector depends on the matrix $H=\sum_{s=1}^{N} H_{s}$, it has no inheritance.

\section{EVALUATION RESUltS AND ANALYSIS}

\section{A. The Selection of Indicators}

In order to comprehensively reflect the environmental pollution in the development of Chinese manufacturing industry, this paper selects five pollutant emission indexes of $\mathrm{SO} 2$ emissions, soot emissions, dust emissions, waste water discharge and solid waste generation as the measurement proxy variables of environmental pollution of manufacturing industry. Because these five indicators can reflect the manufacturing industry pollution emissions from different aspects, they have a good representation.

\section{B. The Evaluation Results and Analysis}

According to the evaluation principle and steps of "vertical and horizontal", the pollution emissions of 28 manufacturing industries in China from 2001 to 2013 are comprehensively evaluated. According to the evaluation results, 28 manufacturing industries are clustered into three categories, namely, light pollution industry, moderate pollution industry and heavy pollution industry by using cluster analysis method in statistics. Among them, the environmental pollution comprehensive index of the light pollution industry $y_{i} \prec 0.35$; the environmental pollution comprehensive index of the moderate pollution industry $0.35 \leq y_{i} \prec 0.4$; the environmental pollution comprehensive index of the heavy pollution industry $y_{i} \geq 0.4$; the results is in Table II.

TABLE II. INDUSTRY CLASSIFICATION OF POLLUTANT EMISSIONS

\begin{tabular}{c|c|l}
\hline Value & Classification & \multicolumn{1}{c}{ Industries } \\
\hline \multirow{3}{*}{$y_{i}<0.35$} & $\begin{array}{c}\text { Light pollution } \\
\text { industry }\end{array}$ & $\begin{array}{l}\text { Communications equipment, computer and electronic equipment manufacturing industry; } \\
\text { tobacco products industry; furniture manufacturing industry; cultural and educational sporting } \\
\text { goods manufacturing; non-ferrous metal smelting and rolling processing industry; } \\
\text { instrumentation and cultural office supplies manufacturing industry, a total of } 6 \text { industries }\end{array}$ \\
\hline \multirow{3}{*}{$0.35 \leq y_{i}<0.4$} & $\begin{array}{l}\text { Moderate } \\
\text { pollution } \\
\text { industries }\end{array}$ & $\begin{array}{l}\text { Chemical raw materials and chemical products manufacturing; pharmaceutical } \\
\text { manufacturing; plastic products; non-metallic mineral products industry; metal products } \\
\text { industry; general equipment manufacturing industry; special equipment manufacturing } \\
\text { industry; electrical machinery and equipment manufacturing industry; textile and garment } \\
\text { footwear manufacturing; leather fur feathers (velvet) and its products industry; the printing } \\
\text { industry and the reproduction of the recording media, a total of 11 industries }\end{array}$ \\
\hline$y_{i} \geq 0.40$ & $\begin{array}{l}\text { Heavy pollution } \\
\text { industry }\end{array}$ & $\begin{array}{l}\text { processing coking and nuclear combustion, paper and paper products industry; transportation } \\
\text { equipment manufacturing; agricultural and sideline food processing industry; food } \\
\text { manufacturing; beverage manufacturing; wood processing and wood and rattan palm grass } \\
\text { products, a total of 11 industries }\end{array}$ \\
\hline
\end{tabular}

From the perspective of sub-industry, the industries classified as heavily polluting are mainly made up of pollution-intensive industries and some traditional means of subsistence manufacturing, which are generally recognized as the largest emitters of emissions. These industries are characterized by a particularly large consumption of resources and particularly large number of pollution emissions, and facing greater difficulties in the green transition, in addition, these industries in the development process have also paid a heavy environmental costs. The traditional means of subsistence manufacturing, has backward production technology, and the industrial technological innovation is slow, and the emission intensity is big, so the impact on the environment is more serious. The industries classified as moderate pollution are mainly heavy and chemical industries. The nature of the heavy chemical industry determines its high energy consumption and high emissions. The industry faces greater difficulty in reducing emissions. The industries classified as light pollution are mainly high-tech industries and clean industries, and the industrial characteristics of clean industries are determined by their low energy consumption and low emissions. The high-tech industry itself has characteristics of strong technological innovation capability, high value-added products, low energy consumption per unit of output and low emissions. With the strengthening of corporate environmental awareness and green production process innovation, pollution emissions will be reduced.

According to the industry differences, the pollution emission of the light pollution industry is the least, followed by the moderate pollution industry and the heavy pollution industry. The average value of the pollution discharge is $0.3079,0.3765$ and 0.4469 respectively. Look at the changes of pollutant emissions from the interior of the industry, before 2011, the light pollution industry's pollution emissions show a significant downward trend, but after 2011 have significant increase. Heavy pollution industry, has the largest pollution emissions and obvious rising trend, the environmental pollution comprehensive indexes rise from 0.3189 in 2001 to 0.5031 in 2013, an increase of 0.18 percentage points. The pollution emissions 
of the moderate pollution industries are lower than those of the heave pollution industries, but significantly higher than that of the light pollution industries. The comprehensive indexes of environmental pollution rise from 0.2837 in 2001 to 0.4686 in 2013, up by 0.19 percentage points.

From the trend of pollutant discharge, the pollution discharge of tobacco products, furniture manufacturing, printing, general equipment manufacturing, metal products, special equipment manufacturing and other industries have experienced an obvious "anti-J" change, pollutant discharge with the passage of time decrease significantly. The industries with obvious increase in pollutant discharge including rubber products, ferrous metal smelting and rolling, transportation equipment manufacturing, food manufacturing, cultural and educational sporting goods manufacturing, non-ferrous metal smelting and rolling, communication equipment, computer and electronic equipment manufacturing, chemical raw materials and chemical products manufacturing, pharmaceutical manufacturing, plastic products, non-metallic mineral products, metal products, wood processing and wood and bamboo rattan palm products, paper and paper products, petroleum processing and nuclear fuel processing industries have "positive $\mathrm{J}$ " changes. The pollution discharge of the industries such as electrical machinery and equipment manufacturing, agricultural and sideline food processing and other industries experience the "U-shaped" change process of "declining first and then rising". Instrumentation and cultural office supplies manufacturing, textile and garment footwear manufacturing, leather fur feathers (velvet) and its products, beverage manufacturing, textile and other industries' pollution emissions change steadily, and have no significant reduction in the trend.

\section{ANALYSIS OF INFLUENCING FaCtORS POLLUTANT DISCHARGE}

\section{A. Index Selection and Model Construction}

This paper studies the influencing factors of environmental pollution, Selected variables are: (1) industry research and development investment ( $R \& D$ ), expresses as the ratio of $R$ \& D investment to main business income of various manufacturing sectors, and includes the lagged term to reflect the time effect of $\mathrm{R}$ \& D investment. (2)energy structure (Elec), expresses as the ratio of the each industry's electricity power consumption to the total energy consumption. (3)ownership structure (Own), expresses as the ratio of the industrial output value of state-owned and state-controlled to total industrial output value. (4) endowment structure $(\mathrm{K} / \mathrm{L})$, expresses as the ratio of the industry net fixed assets to the average number of employees. (5)foreign investment (FDI), expresses as the ratio of the sum of foreign capital and Hong Kong, Macao and Taiwan capital to paid-up capital. (6) environmental regulation intensity (Ruge), expresses as the ratio of the industry pollution control operating costs to the main business income, because the sub-sectors of solid waste management operating costs are missing, so the industry pollution control operating costs include only waste gas and wastewater. (7)industry investment scale (Scal), expresses as the total assets of manufacturing industry at the end of the year.

Taking the abovementioned factors as the explanatory variables, the comprehensive environmental pollution evaluation results (Table II) as the explanatory variables, the panel data measurement model is as follows:

$$
\begin{aligned}
\ln y_{i, t}= & \alpha_{0}+\alpha_{1} \ln \mathrm{R} \& \mathrm{D}_{i, t}+\alpha_{2} \ln \mathrm{R} \& \mathrm{D}_{i, t-1}+\alpha_{3} \ln \mathrm{Elec}_{i, t} \\
& +\alpha_{4} \ln \mathrm{Own}_{i, t}+\alpha_{5} \ln \mathrm{K} / \mathrm{L}_{i, t}+\alpha_{6} \ln \mathrm{FDI}_{i, t} \\
& +\alpha_{7} \ln \mathrm{Ruge}_{i, t}+\alpha_{8} \ln \mathrm{Scal}_{i, t}+\varepsilon_{i, t}
\end{aligned}
$$

Among them, $i$ denotes the industry; $t$ denotes the period; $y_{i, t}$ is the environmental pollution index of industry $i$ in period $t ; \alpha_{1}-\alpha_{8}$ is the regression coefficient; In is the natural logarithm; $\varepsilon_{i, t}$ is the unobservable influence of other random factors not included in the model.

\section{B. The Regression Results and Analysis}

First, the panel data model (6) is examined to determine the form of the model. F test and Hausman test results show that the fixed effect model is superior to the random effect model. In order to eliminate the heteroscedasticity and autocorrelation, this paper adopts the generalized least squares method (GLS) weighted by section to carry on the regression of model (6). The results are shown in Table III.

TABLE III. REGRESSION RESULTS OF MANUFACTURING INDUSTRIES POLLUTION DISCHARGE

\begin{tabular}{c|c|c|c|c}
\hline Variable & $\begin{array}{c}\text { Light Pollution } \\
\text { Industries }\end{array}$ & $\begin{array}{c}\text { Moderate Polluting } \\
\text { Industries }\end{array}$ & $\begin{array}{c}\text { Heavy Polluting } \\
\text { Industries }\end{array}$ & All Industries \\
\hline \multirow{2}{*}{$\mathrm{C}$} & $0.1672^{* *}$ & $1.2043^{*}$ & 0.8315 & $1.2807^{* *}$ \\
& $(0.0183)$ & $(0.1055)$ & $(0.2031)$ & $0.0801)$ \\
\hline \multirow{2}{*}{$\alpha_{1}$} & $-0.6403^{* *}$ & $-0.4627^{*}$ & -0.1924 & $-0.5546^{*}$ \\
& $(0.0029)$ & $(0.0133)$ & $(0.1087)$ & $-0.1139)$ \\
\hline \multirow{2}{*}{$\alpha_{2}$} & $-0.6654^{* * *}$ & $-0.5023^{* *}$ & $-0.2045^{* *}$ & $(0.0154)$ \\
\hline \multirow{2}{*}{$\alpha_{3}$} & $(0.0018)$ & $(0.0045)$ & $(0.0267)$ & $-0.3568^{* *}$ \\
& $-0.2088^{* * *}$ & $-0.3752^{* *}$ & $-0.3943^{* * *}$ & $(0.0279)$ \\
\hline$\alpha_{4}$ & $(0.0451)$ & $(0.0611)$ & $(0.0025)$ & $-0.0588^{* *}$ \\
\hline
\end{tabular}




\begin{tabular}{|c|c|c|c|c|}
\hline & $(0.0244)$ & $(0.1074)$ & $(0.1153)$ & $(0.0415)$ \\
\hline$\alpha_{5}$ & $\begin{array}{l}0.1022^{* *} \\
(0.0561) \\
\end{array}$ & $\begin{array}{l}0.2842^{* *} \\
(0.0344) \\
\end{array}$ & $\begin{array}{l}0.3055^{* * *} \\
(0.0127) \\
\end{array}$ & $\begin{array}{l}0.2643^{* *} \\
(0.0248) \\
\end{array}$ \\
\hline$\alpha_{6}$ & $\begin{array}{l}0.1803^{* *} \\
(0.0069)\end{array}$ & $\begin{array}{l}0.2208^{* *} \\
(0.0137)\end{array}$ & $\begin{array}{l}0.3046^{* * *} \\
(0.0073)\end{array}$ & $\begin{array}{l}0.2893^{* *} \\
(0.0811)\end{array}$ \\
\hline$\alpha_{7}$ & $\begin{array}{l}-0.3103^{*} \\
(0.0822) \\
\end{array}$ & $\begin{array}{l}-0.2564^{*} \\
(0.1049) \\
\end{array}$ & $\begin{array}{l}-0.3814^{* *} \\
(0.0078)\end{array}$ & $\begin{array}{l}-0.3642^{* *} \\
(0.0139) \\
\end{array}$ \\
\hline$\alpha_{8}$ & $\begin{array}{l}0.5827^{* *} \\
(0.0048) \\
\end{array}$ & $\begin{array}{l}0.5603^{* *} \\
(0.0118) \\
\end{array}$ & $\begin{array}{l}0.7809^{* * *} \\
(0.0043)\end{array}$ & $\begin{array}{l}0.6528^{* *} \\
(0.0039) \\
\end{array}$ \\
\hline$A d j R^{2}$ & 0.6723 & 0.7931 & 0.7703 & 0.8054 \\
\hline F statistics & 481.02 & 339.84 & 467.83 & 513.02 \\
\hline $\begin{array}{c}\text { F test of individual } \\
\text { influence }\end{array}$ & $\begin{array}{c}57.34 \\
(0.0015) \\
\end{array}$ & $\begin{array}{c}39.67 \\
(0.0024) \\
\end{array}$ & $\begin{array}{c}56.28 \\
(0.0037) \\
\end{array}$ & $\begin{array}{c}64.18 \\
(0.0037) \\
\end{array}$ \\
\hline Number of samples & 72 & 132 & 132 & 336 \\
\hline
\end{tabular}

Note: The figures in brackets are the standard deviation; $* * *, * * *$ indicate coefficient test $1 \%, 5 \%, 10 \%$ significant respectively.

Regression results show that the improvement of $\mathrm{R} \& \mathrm{D}$ investment, the proportion of electricity consumption, the proportion of the state and the intensity of environmental regulation, can effectively reduce pollution emissions. The share of electricity consumption is negatively correlated with pollution discharge. The increase in the proportion of state-owned and state-controlled industries can significantly reduce pollution emissions. The regression coefficient of environmental regulation intensity is negative, which shows that with the strengthening of environmental regulation policy and the increase of regulation intensity, it will effectively stimulate enterprises to innovate environmental technology, and to some extent, can change enterprises' end management mode of passive treatment after pollution.

Factor endowment structure, foreign investment and the expansion of the scale of investment in enterprises are positively related to the pollution discharge. the increase of capital-labor ratio will promote the transformation from labor-intensive to capital-intensive, while capital-intensive industries are relatively high energy consumption and pollution emissions, which will have a negative impact on reducing pollution emissions. Foreign investment has not played a positive role in reducing pollution emissions. The empirical results also verify the "pollution heaven hypothesis" in the presence of China's manufacturing industry. Industry investment scale's expansion significantly increase the pollution emissions, indicating the current stage of the excessive pursuit of scale expansion, especially high-emission industry scale expansion and investment-led growth extensive model, can not play a positive role in reducing pollution emissions and improving environmental quality.

\section{CONCLUSION AND ENLIGHTENMENT}

By constructing a comprehensive evaluation model of environmental pollution with "three-dimensional" characteristics and scientifically and objectively evaluates the environmental pollution of China's manufacturing industry. Study the influencing factors of pollutant emission. The results show: (1) The industries classified as light pollution are mainly high-tech industries and clean industries; and the industries classified as moderate pollution are mainly heavy and chemical industries; the industries classified as heavy pollution mainly consist of pollution-intensive industries and part of the traditional subsistence manufacturing sector, which are also the focus of energy-saving and emission-reduction monitoring industry. (2) There is a tendency for pollutant emission differences to widen, both within the industry and between different industries. (3) That increasing the R\&D investment, the proportion of clean energy and the proportion of state-owned, the intensity of environmental regulation, are conducive to reducing pollution emissions. Inspirations from the above conclusion are:

From the industry level, we should speed up the construction of green manufacturing system characterized by efficient, clean, energy saving and recycling, and establish a modern enterprise system with the integration of ecological, market-oriented and knowledge-based. From a policy perspective, the relevant functional departments should develop policies and institutional mechanisms conducive to the coordination development of manufacturing and environmental protection. In the process of promoting "Chinese manufacturing 2025" , gradually forming the green innovation mechanism which dominated by green development and conducive to ecological restoration and environmental protection.

China's manufacturing industry has significant heterogeneity characteristics, so the pollutant emission reduction targets and policy measures should take full account of industry differences. For serious polluting industries and heavy polluting industries should appropriately improve the intensity of environmental regulations and standards, develop more stringent regulatory objectives and measures. For the light pollution industry, should be appropriately stabilize the existing regulatory intensity and standards, and strengthen environmental regulation, to prevent the occurrence of opportunistic behavior.

Accelerate the transformation of the manufacturing industry development model and promote the manufacturing industry to upgrade. The first is to adjust and optimize the industry structure, accelerate the manufacturing industry from resource consumption, 
environmental pollution to the innovation-driven shift; the second is to speed up the promotion of structural optimization among the industry, and make the industrial policy appropriately tilt to the high-tech industries which are mainly the light pollution industry and clean industry. to achieve structural reduction through optimizing the energy structure; improve the resources and environment threshold of foreign capital to achieve trade reduction, through strengthening the supervision of foreign-funded enterprises.

\section{ACKNOWLEDEMENTS}

The authors would like to thank the anonymous referees for their constructive comments which substantially improved the presentation of the paper. This research was financially supported by the National Social Science Foundation of research on total factor Productivity of Chinese industry based on energy and environmental constrains( Number: 13BJY037), and Xi' an soft science research project of research on water environmental bearing capacity and restoration measures in Xi'an( Number: SF1505), and Xi'an Jiaotong University Humanities and Social Sciences "Cross-disciplinary category" Fund Project: Two types of social construction research under the background of energy saving, low carbon, environmental protection, NO: sk2014033.

\section{REFERENCES}

[1] X. G. Guo, "A New Comprehensive Evaluation Method - Combinatorial Evaluation Method,” J. Statistical Research, 1995, pp.56-59.

[2] Y. J. Guo, Comprehensive evaluation theory, method and application. Beijing: Science Press, 2007. 